\title{
Validation to Portuguese of the Scale of Student Satisfaction and Self- Confidence in Learning ${ }^{1}$
}

\author{
Rodrigo Guimarães dos Santos Almeida² \\ Alessandra Mazzo ${ }^{3}$ \\ José Carlos Amado Martins ${ }^{4}$ \\ Rui Carlos Negrão Baptista ${ }^{5}$ \\ Fernanda Berchelli Girão ${ }^{6}$ \\ Isabel Amélia Costa Mendes ${ }^{7}$
}

Objective: translate and validate to Portuguese the Scale of Student Satisfaction and SelfConfidence in Learning. Material and Methods: methodological translation and validation study of a research tool. After following all steps of the translation process, for the validation process, the event III Workshop Brazil - Portugal: Care Delivery to Critical Patients was created, promoted by one Brazilian and another Portuguese teaching institution. Results: 103 nurses participated. As to the validity and reliability of the scale, the correlation pattern between the variables, the sampling adequacy test (Kaiser-Meyer-Olkin) and the sphericity test (Bartlett) showed good results. In the exploratory factorial analysis (Varimax), item 9 behaved better in factor 1 (Satisfaction) than in factor 2 (Self-confidence in learning). The internal consistency (Cronbach's alpha) showed coefficients of 0.86 in factor 1 with six items and 0.77 for factor 2 with 07 items. Conclusion: in Portuguese this tool was called: Escala de Satisfação de Estudantes e Autoconfiança na Aprendizagem. The results found good psychometric properties and a good potential use. The sampling size and specificity are limitations of this study, but future studies will contribute to consolidate the validity of the scale and strengthen its potential use.

Descriptors: Simulation, Teaching; Self-Confidence; Personal Satisfaction.

\footnotetext{
1 Paper extracted from doctoral dissertation "Simulação no ensino de enfermagem: validação de instrumentos de ensino-aprendizagem para a língua portuguesa", presented to Escola de Enfermagem de Ribeirão Preto, Universidade de São Paulo, PAHO/WHO Collaborating Centre for Nursing Research Development, Ribeirão Preto, SP, Brazil. Supported by Coordenação de Aperfeiçoamento de Pessoal de Nível Superior (CAPES), Brazil, process \# 2298-14-7.

2 Doctoral student, Escola de Enfermagem de Ribeirão Preto, Universidade de São Paulo, PAHO/WHO Collaborating Centre for Nursing Research Development, Ribeirão Preto, SP, Brazil.

3 PhD, Professor, Escola de Enfermagem de Ribeirão Preto, Universidade de São Paulo, PAHO/WHO Collaborating Centre for Nursing Research Development, Ribeirão Preto, SP, Brazil.

${ }^{4} \mathrm{PhD}$, Professor, Unidade Científica Pedagógica Enfermagem Médico-Cirurgica, Escola Supeior de Enfermagem de Coimbra, Coimbra, Portugal 5 MSc, Adjunct Professor, Unidade Científica Pedagógica Enfermagem Médico-Cirurgica, Escola Supeior de Enfermagem de Coimbra, Coimbra, Portugal.

${ }^{6}$ MSc, RN, Hospital das Clínicas, Faculdade de Medicina de Ribeirão Preto, Universidade de São Paulo, Ribeirão Preto, SP, Brazil.

7 PhD, Full Professor, Escola de Enfermagem de Ribeirão Preto, Universidade de São Paulo, PAHO/WHO Collaborating Centre for Nursing Research Development, Ribeirão Preto, SP, Brazil.
}

Corresponding Author:

Alessandra Mazzo

Universidade de São Paulo. Escola de Enfermagem de Ribeirão Preto

Departamento de Enfermagem Geral e Especializada

Av. Bandeirantes, 3900

Bairro: Monte Alegre

CEP: 14040-902, Ribeirão Preto, SP, Brasil

E-mail: amazzo@eerp.usp.br
Copyright @ 2015 Revista Latino-Americana de Enfermagem This is an Open Access article distributed under the terms of the Creative Commons Attribution Non-Commercial License (CC BY-NC).

This license lets others distribute, remix, tweak, and build upon your work non-commercially, and although their new works must also acknowledge you and be non-commercial, they don't have to license their derivative works on the same terms. 


\section{Introduction}

The use of technologies in teaching has shown to be an important tool to strengthen the learning and competency building of health students and professionals. Among the technologies used, simulation has shown to be an effective teaching-learning strategy as it significantly structures the knowledge.

The use of available Information and Communication Technologies can favor the exchange of practical with updated theoretical-scientific knowledge, besides encouraging the professional to adopt new practices ${ }^{(1)}$. The use of simulation as a pedagogical strategy is an attempt to reproduce the particularities of a certain clinical situation, aiming for a better understanding and management of this condition when it happens in a real-life context. To be affective and reach its full potential, the participants need to consider it as legitimate, authentic and real. As a cognitive and behavioral education strategy, it promotes high levels of self-esteem and self-confidence, as it permits the internalization of information and the satisfaction with the learning process ${ }^{(2)}$.

Simulation allows the students to relate theory and practice to fully prepare them for the moment something similar happens in real life. In the health area, the main purpose is to repeat essential aspects of a clinical situation in a fully controlled environment, which permits errors without causing real damage to the students or the patients under their care ${ }^{(3-4)}$.

The benefits of simulation use in the education of future nursing professionals include building the competences needed to exercise the profession, related to the practice of skills and the development of clinical reasoning. It allows the individual to experience positive and negative aspects of direct patient care, mainly regarding professional safety ${ }^{(5)}$. When included in the study plans of Nursing schools, simulation-based teaching is a way used to achieve this competency building(6).

The use of simulation in teaching provides highquality care to the patients attended, as it promotes and develops the self-confidence and enhances the students' satisfaction levels.

Nowadays, the constructs satisfaction and selfconfidence have aroused great interest in research and have been investigated in a wide range of contexts. To understand the satisfaction construct, one needs to interpret the conjuncture the term is used in, as the word can refer to different actions.
Satisfaction requires the understanding of multidimensional aspects and can be visualized through multiple perspectives ${ }^{(7)}$. It can be defined as a feeling of pleasure or disappointment, resulting from the comparison between the performance expected from the product (or outcome) in relation to the person's expectations; or as the state of affective and cognitive composition in relation to the experience( ${ }^{(8)}$. Covering the users' satisfaction in the teaching sphere has been considered a strong quality indicator in teaching institutions, mainly due to the fact that it appoints the efficacy of the teaching strategies used.

The students' satisfaction with the simulated practice goes beyond the feeling experienced in traditional teaching and minimizes feelings of fear and anxiety about the future profession ${ }^{(9-10)}$.

The etymological root of the word confidence remits to the belief in something or someone, a feeling that permeates the individual's life at different times and in different relationships ${ }^{(11)}$.

The different forms of confidence, whether in society, in the public power, the monetary system and the institutions in general, are necessary, also to maintain the order ${ }^{(12)}$. In the work environment, among colleagues and with the organization itself, confidence offers significant benefits to individuals and their production(13), which implies positive results for the institutions' quality ratios. This idea can be incorporated in the academic environment, where confident students will receive individual and collective benefits, besides contributing to the teaching institutions' quality ratios.

The terms confidence, self-confidence and selfefficacy in the scientific context are often treated as synonyms, but confidence and self-confidence are important elements of the cognitive component of the individual's self-efficacy ${ }^{(14)}$. Emotions and feelings can directly influence the construction of this attribute. Selfconfidence can be interpreted as the conviction that the person needs to be capable of doing or accomplishing something; it refers to the individuals' personal competency to achieve their own objectives ${ }^{(15)}$.

High-fidelity simulation has been appointed as an effective pedagogical strategy thanks to the individuals' recognition of their performance improvements, as it allows the students to gain awareness of their true skills and perceive the positive and negative points, contributing to a more active attitude in the teachinglearning process ${ }^{(16)}$. In that context, as the evidence about simulation use in teaching is still incipient, the use of tools that can measure the gains offered to 
individuals trained in a simulated environment can contribute to the strengthening of the strategy, as well as its improvement ${ }^{(17)}$.

The Scale of Student Satisfaction and SelfConfidence in Learning was created by the National League for Nursing (NLN), a league that works for excellence in nursing education. This scale was developed to measure the individuals' satisfaction and self-confidence gained through high-fidelity simulation. Composed of 13 five-point Likert items, divided in two dimensions (satisfaction/05 items and self-confidence in learning/08 items) ${ }^{(18)}$. The validity of this scale was studied involving 395 students, including 350 women and 45 men, with a mean age of 29 years. The reliability found using Cronbach's alpha corresponded to 0.94 for the satisfaction subscale and 0.87 for the self-confidence subscale.

In that sense, the objective in this study was to translate and validate to Portuguese the Scale of Student Satisfaction and Self-Confidence in Learning.

\section{Method}

The methodological instrument translation and validation study was developed in two phase: the first phase consisted of the translation of the tool, following the criterion proposed by Ferrer et al.(19). Two certified instructors translated the tool to Portuguese and a consensus of the Portuguese version was reached. This version was submitted to a committee of experts. Seven nurses specialized in nursing fundamentals were invited to participate, all of whom were familiar with simulation as a teaching strategy; only four of them attended the meeting. After clarifying the study objective, the judges formalized their consent by signing the informed consent form. The instrument items were classified as valid or not valid. The Content Validity Index (CVI) ${ }^{(20)}$ was calculated and items with CVI of $100 \%$ had their translation maintained in the final version of the tool, while items with CVI inferior to $80 \%$ suffered slight language modifications. To continue this process, two instructors back-translated the tool, being one expert and another native English speaker, for the sake of comparison with the original version. After verifying that the meaning of the tool had not been changed, the semantic validation was accomplished, followed by a pretest with ten nursing graduates who had already experienced simulation as a teaching strategy. The pretest showed that all of them understood the tool properly. After receiving permission from the others of the original scale, this study was submitted for Institutional Review Board approval at the University of São Paulo at Ribeirão Preto College of Nursing and approved under opinion 294.206/2013.

The second phase was the validation of the scale. For this phase, the event: III Workshop Brazil - Portugal: Care Delivery to Critical Patients was created, promoted by a Brazilian educational institution in partnership with a Portuguese educational institution. To participate in this workshop, nurses were invited, whether professionally active or not, holding any graduate degree or not, with our without simulation experience in teaching practice. This free event was disseminated in the print and electronic press, offering 190 places for registration on the institution's website. The participants were offered three optional days to take part; hence, each day of the workshop consisted of 60 participants, being replicated for three days between 08:30 and 18h. All places were filled in advance and, using the e-mails registered, prior reading material was forwarded. Out of the 180 participants who registered, 103 attended the event. The workshop included a theoretical class about care delivery to critical patients and simulation. Brazilian and Portuguese faculty with expertise in simulation and care delivery to critical patients offered the contents. After a theoretical discussion, the participants were divided and submitted to low-fidelity simulated workshops and high-fidelity simulated training, followed by the respective debriefing.

To characterize the subjects, a tool was developed that included the following variables: age, sex, year of undergraduate course conclusion, years of experience, educational background data, employment data and experience with simulated teaching. After taking all phases of the event, the participants were joined in an auditorium and completed the scale. All participants manifested their acceptance to participate in the research through the signing of the informed consent form. Next, the data were coded in Excel worksheets and analyzed using the software Statistical Package for Social Sciences (version 22 for Windows).

\section{Results}

In the first phase of the study, questions 2, 5, 6 and 13 obtained CVI scores inferior to $80.0 \%$, so that their formulation was modified. The word instrutor was replaced by professor, as the roles taken in the simulated environment in the United States differ from the roles developed in the simulated environment in Brazil and Portugal. In these countries, a single person tends to serve as teacher, instructor and 
facilitator, who is the teacher. After this adaptation, the rest of the process happened regularly.
The final version of the scale in Portuguese is displayed in Figure 1.

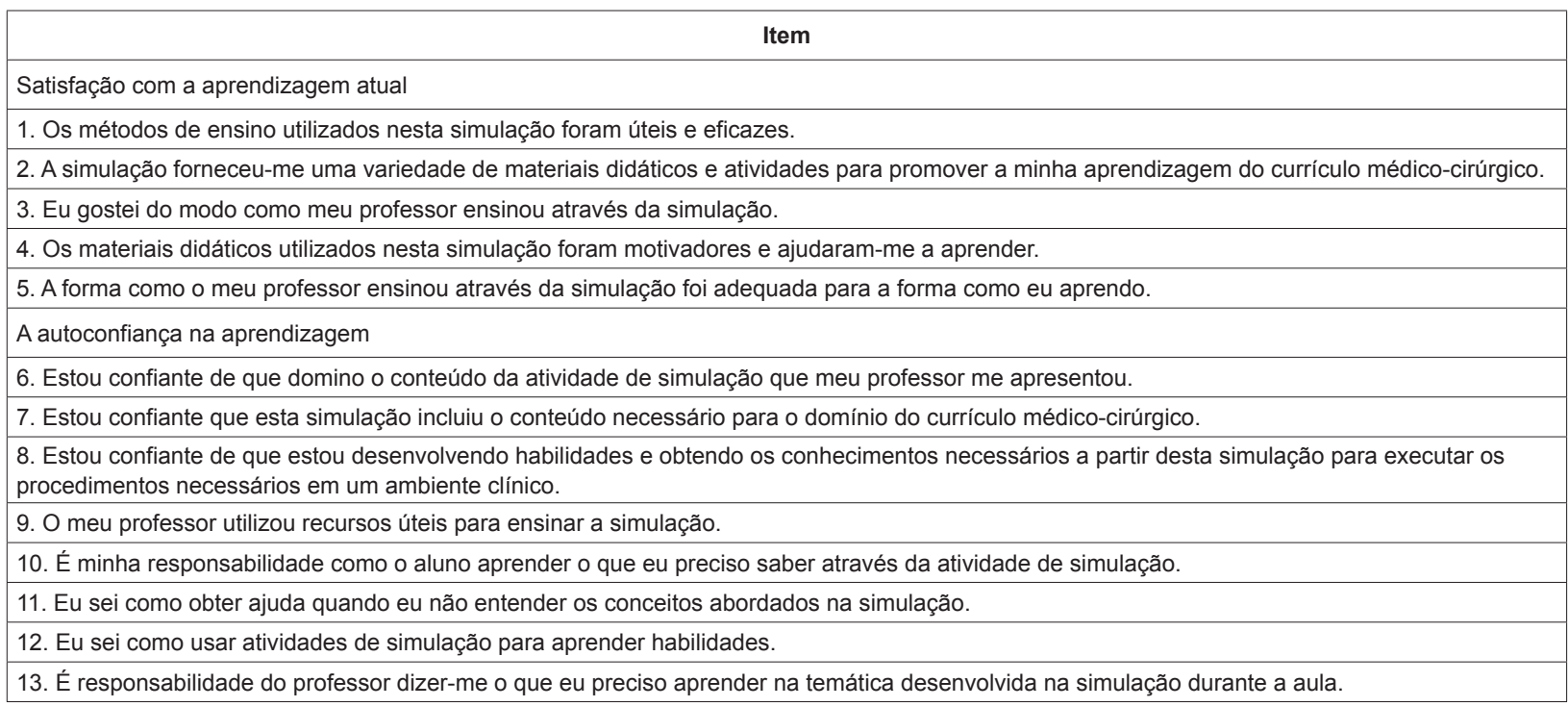

Figure 1 - Description of the items of the Escala de Satisfação de Estudantes e Autoconfiança na Aprendizagem, Ribeirão Preto, São Paulo, Brazil, 2014

In the second phase, among the 103 nurses who participated in the workshop, $100.0 \%$ agreed to participate in the research and made up the study sample. Most participants, 90 (87.4\%), were female and the mean age was 32.1 years, with a mean age of 20 and a maximum of 57 years. As for education, on average, their course conclusion year was 2005. Sixty-four $(62.1 \%)$ held or were taking a Lato Sensu specialization program, $47(45.7 \%)$ held or were taking a Master's program, 20 (19.4\%) held or were taking a Ph.D. and $20(19.4 \%)$ had not taken any kind of graduate program. Concerning their professional activity, 77 (74.8\%) were professionally active, $48(46.6 \%)$ in clinical nursing, 23 (22.3\%) were faculty and six (5.8\%) service managers. As regards experience in simulated teaching, 52 (50.5\%) indicated they were not familiar with simulation as a teaching strategy and $51(49.5 \%)$ said they were familiar. What care delivery to critical patients is concerned, 83 participants (80.6\%) informed having first delivered care directly to the patient in care practice and only $20(19.4 \%)$ delivered that care in the laboratory environment. As to the feeling of preparedness for that care, $86(83.5 \%)$ informed they did not feel prepared, while only 17 (16.5\%) affirmed feeling prepared to cope with that situation.

Concerning the validity and reliability of the scale, the correlation pattern between the variables, verified using the correlation matrix, showed $25.4 \%$ of correlations superior to 0.30 . The coefficient of the sampling adequacy test (Kaiser-Meyer-Olkin) was 0.83 , Bartlett's sphericity test $<0.001$ and the coefficient on the anti-image matrix ranged between 0.77 and 0.89 .

What the extraction of the factors is concerned, the total explained variance showed three eigenvalues superior to 1.00 , with a cumulative percentage that explained more than $60.0 \%$ of the total variance, suggesting that the scale could be divided in three factors.

As to the factor rotation, the communality test demonstrated that items 4, 6, 8 and 10 obtained lower estimates $(0.50)$ but that, due to their proximity, they could be maintained in the scale. The estimate for item was (0.18), suggesting the removal of this item from the scale. To verify the satisfaction and selfconfidence factors with the learning, exploratory factor analysis with orthogonal Varimax rotation and Kaiser normalization was applied, as demonstrated in Table 1. 
Table 1 - Saturation matrix of the items in the factors for the orthogonal Varimax rotated solution with Kaiser normalization ( $n=103$ ), Ribeirão Preto, São Paulo, 2014

\begin{tabular}{|c|c|c|}
\hline Items & $\begin{array}{c}\text { Factor } 1 \\
\text { Satisfaction }\end{array}$ & $\begin{array}{c}\text { Factor } 2 \\
\text { Self-confidence in learning }\end{array}$ \\
\hline 1 & 0.81 & -0.02 \\
\hline 2 & 0.79 & 0.11 \\
\hline 3 & 0.82 & 0.18 \\
\hline 4 & 0.63 & 0.22 \\
\hline 5 & 0.66 & 0.36 \\
\hline 6 & 0.20 & 0.67 \\
\hline 7 & 0.24 & 0.73 \\
\hline 8 & 0.34 & 0.56 \\
\hline 9 & 0.73 & 0.29 \\
\hline 10 & 0.23 & 0.63 \\
\hline 11 & 0.14 & 0.70 \\
\hline 12 & 0.11 & 0.73 \\
\hline 13 & -0.01 & 0.43 \\
\hline
\end{tabular}

In the distribution of the scale in two factors, it was observed that item 9 in this sample behaved better in factor 1 than in factor 2, differently from the original scale. Hence, in this study, after a detailed analysis of the item, it was included in the student satisfaction factor.

The internal consistency analysis of the factors using Cronbach's alpha demonstrated coefficients of 0.86 for the satisfaction construct (06 items); 0.77 for the self-confidence in learning construct (07 items) and 0.84 for the general scale.

Pearson's correlation coefficient showed a weak correlation (0.47) between satisfaction and selfconfidence in learning $(p<0.01)$, indicating that these factors are not correlated.

In Table 2, a high correlation is observed between practically all items and the total scale, except in item 13.

Table 2 - Homogeneity statistics of the items and Cronbach's internal consistency coefficients of the students' satisfaction and self-confidence in learning $(n=103)$, Ribeirão Preto, São Paulo, 2014

\begin{tabular}{|c|c|c|c|c|}
\hline Items & Mean & Standard Error & $\begin{array}{c}\text { Correlation with total } \\
\text { (corrected) }\end{array}$ & $\begin{array}{c}\text { Alpha if the item were } \\
\text { eliminated }\end{array}$ \\
\hline 1 & 4.70 & 0.54 & 0.41 & 0.84 \\
\hline 2 & 4.69 & 0.59 & 0.53 & 0.83 \\
\hline 3 & 4.73 & 0.49 & 0.59 & 0.83 \\
\hline 4 & 4.74 & 0.56 & 0.49 & 0.83 \\
\hline 5 & 4.69 & 0.54 & 0.61 & 0.83 \\
\hline 6 & 4.05 & 0.76 & 0.55 & 0.83 \\
\hline 7 & 4.16 & 0.85 & 0.63 & 0.82 \\
\hline 8 & 4.46 & 0.61 & 0.57 & 0.83 \\
\hline 9 & 4.68 & 0.49 & 0.62 & 0.83 \\
\hline 10 & 4.42 & 0.81 & 0.52 & 0.83 \\
\hline 11 & 4.35 & 0.72 & 0.53 & 0.83 \\
\hline 12 & 4.23 & 0.76 & 0.53 & 0.83 \\
\hline 13 & 3.55 & 1.12 & 0.24 & 0.86 \\
\hline
\end{tabular}


Table 3 displays descriptive statistics of the scale factors.

Table 3 - Descriptive statistics of factors of the Escala de Satisfação dos Estudantes e Autoconfiança na Aprendizagem ( $n=103$ ), Ribeirão Preto, São Paulo, 2014

\begin{tabular}{lcc}
\hline & $\begin{array}{c}\text { Factor } \mathbf{1} \\
\text { Satisfaction }\end{array}$ & $\begin{array}{c}\text { Factor 2 } \\
\text { Self-confidence in learning }\end{array}$ \\
\hline Mean & 4.70 & 4.17 \\
Median & 5.00 & 4.14 \\
Mode & 5.00 & 4.00 \\
Standard Error & 0.41 & 0.53 \\
Variance & 0.17 & 0.28 \\
Minimum & 3.17 & 2.43 \\
Maximum & 5.00 & 5.00 \\
Percentiles & & \\
25 & 4.50 & 3.86 \\
50 & 5.00 & 4.14 \\
75 & 5.00 & 4.57 \\
\hline
\end{tabular}

\section{Discussion}

The Portuguese version of the scale of Student Satisfaction and Self-Confidence in Learning was called: Escala de Satisfação dos Estudantes e Autoconfiança com a Aprendizagem. The subject students in the name of the scale was kept, in line with the original scale. According to the original authors, however, the scale can be applied to any individual in the education process, without any restriction.

The psychometric tests showed a high correlation between the variables and a good sampling adequacy for the study. As to the extraction of the factors, despite the mathematical suggestion to divide the scale in three factors, as the tool was short and contained few items, the recommendations of the original tool were followed, maintaining the division of the scale in two factors. The need for further research on the number of factors in other studies is highlighted, as well as regarding the omission of item 13, which was present in the original scale and gave strong evidence for removal from the tool in all tests applied. In this study, the characteristic of this item may have been impaired by the non consideration of the theoretical part of the workshop as class contents ${ }^{(21)}$. Item 9 in the factor analysis behaved better in the student satisfaction factor than in the selfconfidence with learning factor. In the analysis of the formulation of this item, a trend is observed for the item to better assess satisfaction with the resources used in high-fidelity simulation than self-confidence. Therefore, in this study, this adaptation was made and the reconsideration of the behavior of this item in further research is suggested.

The internal consistency coefficients of the factors satisfaction and self-confidence in learning in this study were lower than the coefficients in the original study, but are in line with other studies ${ }^{(22-25)}$.

In the same sense, concerning the level of significance, these findings are similar to the findings by Smith and Roehrs ${ }^{(25)}$, in which the 68 nursing students investigated who used high-fidelity simulation as a teaching strategy showed high satisfaction and self-confidence in learning coefficients. The study appoints that the individual's satisfaction in learning in the simulated environment depends on the appropriate structuring of the strategy, and that a design needs to be followed that includes: objectives, problem solving, student support and debriefing. Any errors in this construction may compromise the teaching process. In that sense, the teacher responsible for the elaboration of this structure needs to elaborate it cautiously and respect the principles and guidelines established, with a view to the effectiveness of low, medium or highfidelity simulation.

\section{Conclusion}

Individuals' satisfaction and self-confidence in learning are important constructs in the teaching environment. Measuring them can be a strong sign for the use and assessment of teaching strategies.

In this study, the scale Student Satisfaction and Self-Confidence in Learning was translated and validated for the Portuguese language, now called Escala de Satisfação de Estudantes e Autoconfiança com a Aprendizagem, used punctually in high-fidelity simulation. The scale revealed good psychometric properties that revealed a good potential use of the tool.

The limitations in this study are the sampling size and specificity. Nevertheless, future studies will contribute to consolidate the validity of the scale and strengthen its potential use.

\section{Acknowledgements}

To the research subjects for having participated in this study. 


\section{References}

1. Nagliate PC, Rocha ESB, Godoy S, Mazzo A, Trevizan MA, Mendes IAC. Individualized teaching programming for a virtual learning environment: development of content concerning nursing records. Rev. Latino-Am. Enfermagem. 2013;21(spe): 122-30.

2. Camacho HM. Simulación cibernética en las ciencias de la salud. Recuento histórico en el mundo y en Colombia y su impacto en la educación. Rev Colomb Cardiol. 2011; 18(6):297-304.

3. Martins JCA, Mazzo A, Baptista RCN, Coutinho VRD, Godoy S, Mendes IA, et al. A experiência clínica simulada no ensino de enfermagem: retrospectiva histórica. Acta Paul Enferm. 2012;25(4):619-25.

4. Ireland M. Assisting students to use evidence as a part of reflection on practice. Nurs Educ Perspect. 2008;29(2):90-3.

5. Hovancsek M, Jeffries PR, Escudero E, Foulds BJ, Husebo SE, Iwamoto $Y$, et al. Creating simulation communities of practice: an international perspective. Nurs Educ Perspect. 2009;30(2):121-5.

6. Martins JCA, Baptista RCN, Coutinho VRD, Mazzo A, Rodrigues MA, Mendes IAC. Self-confidence for emergency intervention: adaptation and cultural validation of the self-confidence scale in nursing students. Rev. Latino-Am. Enfermagem. 2014;22(4): 554-61.

7. Whitten $P$, Love $B$. Patiente and provider satisfaction with the use of telemedice: overview and rationale for cautions enthusiasm. J Postgrad Med. 2005;51(4):294-300.

8. Whitman DS, Rooy DLV, Viswesvaran C. Satisfaction, citizenship behaviors, and performance in work units: a meta-analysis of collective construct relations. Pers Psychol. 2010;63(1):41-81.

9. Ying LS, Yiwen K, Rabiah, D. Easing student transition to graduate nurse: a simulated professional learning environment (SIMPLE) for final year student nurses. Nurs Educ Today. 2014;34(3):349-55.

10. Alfes CM. Evaluating the use of simulation with beginning nursing students. J Nurs Educ. 2011;50(2):89-93.

11. Valentim IVL, Kruel AJ. A importância da confiança interpessoal para a consolidação do programa de saúde da família. Cienc Saúde Coletiva. 2007;12(3):777-88.

12. Lewis D, Weigert A. A trust as a social reality. Social Forces. $1985 ; 63(4): 967-85$.

13. Morrow Jr JL, Hansen MH, Pearson AW. The cognitive and affective antecedents of general trust within cooperative organizations. JMI. 2004;16(1):48-64.

14. Leigh GT. High-fidelity patient simulation and nursing students self-efficacy: A review of literature. J Nurs Educ Scholarsh. 2008;5(1):1-16.

15. Bandura A. Social foundations of thought and action: a social cognitive theory. Englewood Cliffs, NJ: PrenticeHall; 1986 .
16. Baptista RCN, Martins JCA, Pereira MFCR, Mazzo A. Simulação de alta-fidelidade no curso de enfermagem: ganhos percebidos pelos estudantes. Rev Enfer Ref. 2014; 4(1):135-44.

17. Jorge BM, Almeida RGS, Souza Jr VD. Tendências Atuais na Investigação em Simulação. In: Martins JCA, Mazzo A, Mendes IAC, Rodrigues MA. A Simulação no Ensino de Enfermagem. Ribeirão Preto: SOBRACEn; 2014. 18. Jeffries PR, Rizzolo M.A. National League for Nursing/Leardal project summary report: Designing and implementing models for the innovative use of simulation to teach nursing care of ill adults and children: A national, multi-site, multi-method study. New York: National League for Nursing; 2006.

19. Ferrer M, Alonso J, Prieto L, Plaza V, Monso E, Marrades $\mathrm{R}$, et al. Validity and reliability of the $\mathrm{St}$ George's Respiratory Questionnaire alter adaptation to a different language and culture: the Spanish example. Eur Respir J. 1996;9(6):1160-6.

20. Polit DF, Beck CT. The Content validity index: are you sure you know what's being reported? critique and recommendations. Res Nurs Health. 2006;29(5):489-97. 21. Megel ME, Black J, Clark L, Carstens P, Jenkins LD, Promes J, et al. Effect of high-fidelity simulation on pediatric nursing students'anxiety. Clin Simulation Nurs. 2012; 8(9):419-28.

22. Xiaoying M. BSN Students'Perception of Satisfaction and Self-confidence After a Simulated Mock Code Experience: A Descriptive Study [tese na internet]. Califórnia (EUA): Cedarville University; 2013. [acesso 17 jul 2014]. 38 p. Disponível em: http://digitalcommons. cedarville.edu/nursing_theses/2/

23. Hall RM. Effects of high fidelity simulation on knowledge acquisition, self-confidence, and satisfaction with baccalaureate nursing students using the solomonfour research design [Internet]. Tennessee: Tennessee State University; 2013. [acesso 23 jul 2014]. 91 p. Disponível em: http://dc.etsu.edu/cgi/viewcontent. cgi? article $=3646 \&$ context $=$ etd

24. Cardoza MP, Hood PA. Comparative study of baccalaureate nursing student self-efficacy before and after simulation. Comput Inform Nurs. 2012;30(3):142-7. 25. Smith SJ, Roehrs CJ. High-fidelity simulation: factors correlated with nursing student satisfaction and self-confidence. Nurs Educ Perspect. 2009;30(2):76-8.

Received: Sept. $22^{\text {nd }} 2014$ Accepted: Apr. $4^{\text {th }} 2015$ 